\title{
Dostales y compromisos de las Bodas de Oro
}

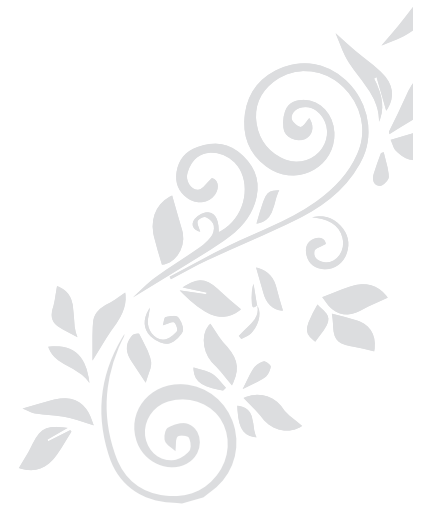

.
更 ste año la coincidencia de dos fechas memorables puso de manifiesto el intenso desarrollo de nuestra vida institucional. A lo largo de 2019 estamos celebrando las Bodas de Oro de nuestra casa de estudios y conmemoramos el primer siglo de la partida de nuestro patrono, don Ricardo Palma. A su lado, estamos también recordando el Centenario del fallecimiento del notable y polifacético Abraham Valdelomar, y, aún el Cincuentenario de la muerte de quien fuera uno de los iniciadores de la literatura andinoagraria antifeudal: José María Arguedas.

En este medio siglo de historia, la Universidad Ricardo Palma ha estado ligada al desarrollo de la ciencia y la cultura del país, produciendo en tal sentido investigaciones de beneficio social y además organizando grandes eventos académicos y culturales, como el Congreso Homenaje Internacional: Aníbal Quijano. Descolonialidad del Poder Hoy, en el que se revisó el legado intelectual del eminente teórico y político peruano fallecido en mayo del ańo pasado. En el ámbito de la transdisciplinariedad destacamos la conferencia Modelado Basado en Agentes: Usando Inteligencia Artificial y Datos Grandes en las Ciencias Sociales, que confirmó una vez más el enriquecedor diálogo entre campos académicos distintos.

Asimismo, este año nuestra Casa de estudios cumplió un rol importante en la reflexión sobre el pensamiento americanista en tiempos de la Reforma universitaria de 1918 y su proyección en el Perú, organizando una muestra y una conferencia sobre el Centenario de tan importante hecho de enorme repercusión en la vida universitaria continental y peruana. En la misma línea de "exposición virtual", fotográfica, destacamos "De tradiciones y gestiones: el legado de Ricardo Palma a la sociedad peruana".

Fueron también notables los reconocimientos de nuestra universidad a las labores de intelectuales, artistas y profesionales peruanos de primer nivel, a través de congresos, conferencias y charlas; así como de entregas de medallas y nombramiento de doctores honoris causa, como fueron los casos del notable arquitecto Juvenal Baraco, docente de nuestra universidad, y del ilustre teólogo Gustavo Gutiérrez, la figura más relevante de la Teología de la Liberación. Estos reconocimientos son también importantes por la promoción y difusión del pensamiento y obra de tan eminentes personalidades.

En el campo del arte, en nuestro Mes de aniversario, en julio, uno de los altos intelectuales de nuestra universidad, poeta y poliédrico hombre de arte, el doctor Manuel Pantigoso, ofrendó una obra dramática sin par, Luz de cristales en la roca; Tinkuy del Fiat Lux, creada exclusivamente en homenaje a la Universidad Ricardo Palma y llevada a escena con un esfuerzo y resultado extraordinarios.

Fue un año intenso y satisfactorio en todos los campos. En la Ciencia, en las Ingenierías, en el Arte y en las Letras, nuestra universidad descolló como fuente de nuevos conocimientos y gran promotora de la formación integral de profesionales con alto nivel académico y sólidos valores humanos. Precisamente, este es un aspecto básico para quienes abren este nuevo número de la revista Tradición y pueden comprobar su variedad y profundidad de temas. 
No podemos dejar de nombrar la XX Asamblea General de la Unión de Universidades de América Latina y el Caribe - UDUAL, que auspició la Universidad Ricardo Palma con la asistencia de rectores de América Latina y el Caribe. En este evento de gran proyección académica americanista se priorizó la construcción de una agenda regional para la educación superior hasta el 2030.

Hoy, medio siglo después de su fundación, la Universidad Ricardo Palma alberga alrededor de doce mil estudiantes y tiene centenares de profesores que atienden las funciones de la enseñanza, la investigación y la difusión del conocimiento en áreas como Ciencias Económicas y Empresariales, Arquitectura y Urbanismo, Ciencias Biológicas, Derecho y Ciencias Políticas, Humanidades y Lenguas Modernas, Ingeniería, Psicología y Medicina Humana. Los docentes y estudiantes de cada una de nuestras áreas académicas forman parte fundamental de nuestro patrimonio universitario, pues constituyen el elemento transversal en el cumplimiento de nuestra misión de transmitir la cultura y el conocimiento superior por medio de la enseñanza y de su progreso a través de la investigación. La revista Tradición es una buena muestra de esta labor.

Iván Rodríguez Chávez

Rector de la URP 